\title{
Design Thinking's resources for in-situ co-design of mobile games
}

\author{
Cecilia Challiol \\ UNLP, Facultad de Informática, LIFIA \\ and also CONICET \\ La Plata, Buenos Aires, Argentina \\ ceciliac@lifia.info.unlp.edu.ar \\ Facundo I. Mendiburu \\ UNLP, Facultad de Informática, LIFIA \\ La Plata, Buenos Aires, Argentina \\ fmendiburu@lifia.info.unlp.edu.ar \\ Francisco Goin Plexevi \\ UNLP, Facultad de Informática, LIFIA \\ La Plata, Buenos Aires, Argentina \\ fgoin@lifia.info.unlp.edu.ar
}

\section{Estevan Gomez-Torres}

UTE, Facultad de Ingeniería, Carrera de Ingeniería en Informática and also Facultad de Informática, UNLP

Quito, Ecuador

estevan.gomez@ute.edu.ec, estevan.gomezt@info.unlp.edu.ar

\author{
Franco M. Borrelli \\ UNLP, Facultad de Informática, LIFIA \\ La Plata, Buenos Aires, Argentina \\ fborrelli@lifia.info.unlp.edu.ar
}

Candela M. Rouaux Servat

UNLP, Facultad de Informática, LIFIA

La Plata, Buenos Aires, Argentina

crouaux@lifia.info.unlp.edu.ar

\author{
Diego H. Orellano \\ UNLP, Facultad de Informática, LIFIA \\ La Plata, Buenos Aires, Argentina \\ dorellano@lifia.info.unlp.edu.ar \\ Silvia E. Gordillo \\ UNLP, Facultad de Informática, LIFIA \\ and also CICPBA \\ La Plata, Buenos Aires, Argentina \\ gordillo@lifia.info.unlp.edu.ar
}

\begin{abstract}
Location-based Mobile Games have been growing in popularity in recent years. But these are widely explored only for outdoor spaces, since it has the advantage of using GPS data to obtain the user's current location. There is no unified solution to sense the user's location in indoor spaces; so, games for these spaces are little explored. The design of Location-based Mobile Games, in many cases, requires the participation of multidisciplinary teams; so, they are co-designed by a group of people. However, there is no clear way of knowing how this codesign should be conducted. The aim of this paper is to propose a conceptual framework for in-situ co-design for indoor spaces on Location-based Mobile Games through the use of Design Thinking's resources. This conceptual framework could help facilitators with this kind of experience to consider what resources can be useful to this task. An experience of in-situ co-design of a Location-based Mobile Game for indoor spaces is presented using the proposed framework. In addition, a discussion is generated in relation to this kind of co-design.
\end{abstract}

Keywords - in-situ co-design; location-based mobile games; multidisciplinary teams; authoring tools

\section{INTRODUCTION}

Location-based Mobile Games have been growing in popularity in the last few years, as it is the case of Pokemon Go [1]. This kind of games usually obtain the user's current location using GPS, and based on it, information or actions are enabled or triggered.

The complexity of the design and implementation of these games increases when they are intended to be used in indoor spaces; since there is no unified solution to sense the user's location in this kind of spaces [2], as it occurs in outdoor spaces with GPS. In [2] the authors suggest WLAN (as an indoor sensing mechanism) as the best option for this kind of applications; however, there is no consensus yet on this subject. Moreover, a question that arises is how to ensure that the dynamism of the game is not lost, for example, because of the latency generated when the user's location is updated.

Currently, a wide range of Location-based Mobile Games use GPS to obtain users' locations. For example, City Conqueror [3] is a location-based mobile multiplayer game inspired by the board game Risk (in which a player conquers countries on a world map, deploys units to defend her or his countries and 
attacks countries owned by other players). This game was created to investigate how location-based games are integrated into a player's daily life. This kind of games could be used not only for entertainment, but also in other domains such as education. In [4], the authors describe opportunities and challenges of using mobile location-based games in education. Note that, each kind of game has its own features which generate the complexity involved in the design phase of each one.

Location-based Mobile Applications, which include Location-based Mobile Games, could be designed in-situ or using a map (virtually) [5]. In-situ design requires the designer to walk through the physical space, and identify the relevant locations where information or services will be provided to the users. This kind of design allows to appreciate environment's features which could be beneficial for the application. The mapbased or virtual design is done remotely without requiring the designer to be at the place where the application will then be used; in this kind of design relevant locations are marked on the map. It is worth mentioning that the in-situ design is in the first stages of the exploration; only a few works have started to research about it.

In the last years, some guidelines and tools have been designed to create Location-based Mobile Games in order to facilitate the complexity involved in this task. For example, in [6], an authoring tool for building location-based mobile games enhanced with augmented reality capabilities is presented. This authoring tool enables non-programmer users to design, build, and run location-based mobile games for outdoor spaces. In [7], the design of Location-based Mobile Games is proposed as a construction that involves a group of people (in some cases multidisciplinary groups); so, this kind of games could be codesigned in order to enrich them with multiple perspectives provided by the participants. Two practical examples of codesign Location-based Mobile Games for outdoor spaces are described in [7]. The existing guidelines and tools are focused on Location-based Mobile Games for outdoor spaces. This drives us to explore how to co-design this kind of games for indoor spaces.

Another key point is the innovation in Location-based Mobile Games which is fundamental. Therefore, this should be considered while they are being co-designed. However, oftentimes this feature is lost when they are designed. A discipline that has emerged in recent years in the field of innovation is Design Thinking [8] which focuses on "using the designer's sensibility and methods to match people's needs with what is technologically feasible and what a viable business strategy can convert into customer value and market opportunity".

The motivation of this paper arises from the open areas of research mentioned above. We wish to offer clear guidelines which allow to conduct in-situ co-design of this kind of games, particularly in indoor spaces; adding innovative features.

The aim of this paper is to propose a conceptual framework for in-situ co-design of Location-based Mobile Games for indoor spaces which use some Design Thinking's resources to this task. This framework could be used to help facilitators of these types of experiences to consider what resources can be useful for this co-design.
An experience of in-situ co-design of a Mobile Game based on Positioning for an indoor space using the proposed conceptual framework is presented. It describes a possible way of conducting this kind of co-design and the considerations that must be taken into account.

In addition, a discussion space is generated in relation to this kind of co-design, for example, how authoring tools could assist the co-design task or how the co-design carried out can be taken to specific implementations allowing this games to adapt to new requirements or evolve over time [9].

This paper is structured as follows. In Section 2 some related works are detailed. In Section 3, it is presented the conceptual framework for in-situ co-design of Location-based Mobile Games for indoor spaces which use some Design Thinking's resources to this task. An in-situ co-design experience of Location-based Mobile Game for indoor spaces is described in Section 4. In Section 5 a discussion is generated in relation to this kind of co-design. Conclusions and future works are presented in Section 6.

\section{RELATED WORKS}

In the recent years, a wide range of Location-based Mobile Games have been explored, some of these have become popular as it is the case of Pokemon Go [1]. The following describes some games that have different features in order to make it easier for the reader to understand the varied range of aspects that should be handled in the co-design phase.

In [10] a mobile virtual reality game is presented which proposes a tour of the archaeological Avebury site to discover hidden virtual "treasures" while the users walk; these virtual "treasures" could be discovered in a certain relevant location of the real physical space. In this case, the location is obtained using the device's GPS. The authors also mention in [10] that the game is inspired by Neolithic legends of the area, however, there is no detail of how it has been designed.

In [11] four experiences of the QuesTInSitu game are presented. This game provides location educational questions (which are created by teachers and located using a map). As the students walk through the physical outdoor space, they receive the questions on their mobile devices, which are answered in an in-situ way (where they are). Note that, QuesTInSitu uses the GPS of the students' mobile devices to locate them. In [11] is mentioned that the co-design phase requires teachers to visit the physical places to be able to define the relevant locations in which to provide each question of each of these four experiences. The authors mention that this is an iterative task to refine each experience, but it is not detailed how this process was carried out.

In [12] is presented a mobile experience combined with theatrical interventions which are performed by real actors. Users move through a physical space. When they reach each relevant location, they should read a $\mathrm{QR}$ code; as a result, they receive the task that they should carry out according to the theatrical intervention that happens later in that place. In [12] is mentioned that the co-design was carried out jointly between a theatre director and technologists. This task involves visiting the 
building to define, for example, the location of the performances.

In [13] the authors define a location narrative which has four characters. Each one has certain information; in addition, the decisions of a character impact on the information that the other characters would receive. The authors decided to explore in [13] the complexity of this kind of stories where there are several readers experiencing different versions of the same story, and how they can impact on the story of the other characters. In this process, game designers, technologists as well as writers have been involved.

For the before mentioned games, no details were provided on how they were designed. In some of them, the authors mention the importance of a walk through the physical spaces in order to appreciate the best places to provide the stories or information about the games.

Nowadays, different authoring tools have been developed that facilitate the creation of this kind of games. In [14] an authoring tool is presented which allows a group of students to select the relevant location from a map. Note that, these locations are agreed by the whole group. The biggest challenge in this task is to define significant content in each relevant location according to the sequence of the game. The students generate content, but often this does not have a common thread. This may be because there is no clear guide to help them in this task.

Another authoring tool is presented in [15] which allows a multidisciplinary team (composed of game designers, technologists, and writers) to create location-based narratives. The first sketch of the relevant locations is defined in-situ, then the team defines the narratives on a computer. Sometimes, these creations require revisiting the places. The biggest challenge for game designers and technologists is to understand how writers define stories. Thus, techniques that allow to empathize among all the actors involved in the co-design experience are required in order to take advantage of the expertise of all participants.

Design Thinking defines four phases according to the Design Council framework [16] ordered as: Discover, Define, Develop and Deliver (prototype). Discover and Develop phases suggest "divergence" activities because they open different possibilities. As complementary, Define and Deliver phases suggest "converge" activities, so, it reduces the options. These phases as a whole are known as the double diamond process, which takes the divergence and convergence activities into account. Note that, Design Thinking involves several stakeholders in the process, and offers and tests ideas rapidly. It supports iterative idea generation and constant review, helping to obtain prototypes quickly. In [8] suggests that Design Thinking is best thought of as a process of three spaces (Inspiration, Ideation, and Implementation) and not a sequence of orderly stages and they are iterative.

In [17] the use of Design Thinking's strategies to design mobile applications is explored. To do that, the authors carry out the two first stages presented in [17], as Inspiration and Ideation. For the Inspiration stage, the Persona and Empathy Map templates are used. Brainstorming and co-workshop are used for the Ideation stages. The authors are focused on exploring how to carry out Design Thinking's strategies in the classroom in order to prepare the IT's students for the challenges of the new demand of companies, in particular, for innovation centers in person-design.

In [18] the authors present the challenges of teaching to the new generation of IT students. The authors describe an in-situ co-design experience of a mobile application. They have explored Brainwriting [19] during the diverge activity and the Cost-Benefit Matrix [20] during the converge activity. Note that, Brainwriting [19] consists of a group of participants writing ideas on a sheet, for two or three minutes, then rotating the sheets to their left. This is repeated for four or five times. Participants may re-write ideas based on what they receive or create new ones. According to [19], Brainwriting produces a more comfortable atmosphere than Brainstorming because all the ideas are valid in this phase and there is no discussion about them.

\section{CONCEPTUAL FRAMEWORK FOR IN-Situ CO-DESIGN FOR MOBILE GAMES IN INDOOR SPACES}

We have been working on the topic of mobile applications for more than 10 years. We have proposed in [21] a model approach to handling variability in context-aware mobile applications. We have been exploring sensing mechanisms for this kind of application [22]. A taxonomy of variability for building approaches for context-aware mobile applications has been presented in [23]. We have been creating some authoring tools for this kind of applications [24], [25], [26]. In addition, we have been exploring co-design in the educational domain [27].

Our experience and the existing literature has allowed us to incorporate the knowledge to propose a conceptual framework for the in-situ co-design of Location-based Mobile Games for indoor spaces which use some Design Thinking's resources to this task. The proposed framework defines four phases, two of divergences and two of convergences, inspired by the double diamond used by the Design Thinking framework [16] but resignifying it according to the domain of Location-based Mobile Games. The framework is shown in Figure 1. More details of each of the phases of Figure 1 are described below.

- Discover (divergent phase) allows to create all possible relevant locations that could be of interest for a game.

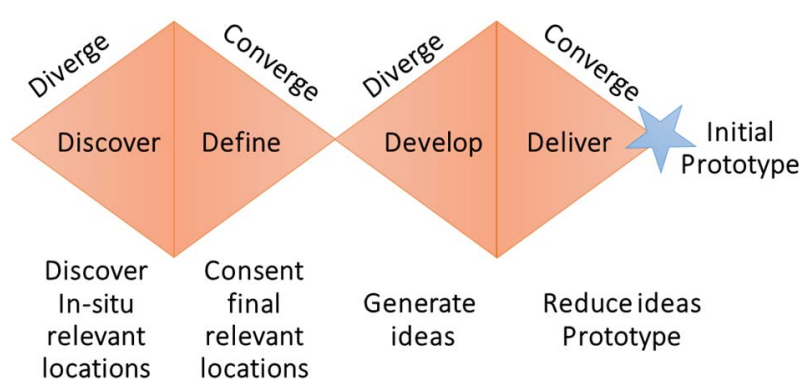

Fig. 1. Our Conceptual Framework for in-situ co-design of mobile games in indoor spaces. 
This phase is recommended to be carried out individually by the co-design experience's participants, because it allows to create more possibilities.

Material for this phase: provide maps of each floor of the building where the design is being carried out and in some way allow to mark the relevant locations. In case the participants require to know more about the final user's profile, it is recommended to use some techniques such as Persona [28] and Empathy Map [29] templates.

- Define (converge phase) involves the agreement of the relevant locations that will be considered in the game. It is advisable to work this in groups, so the group agrees which one of their locations will be considered in the game.

Material for this phase: Provide some way to document the agreed relevant locations.

- Develop (divergent phase) generates ideas in groups, in relation to the game. For this phase, Brainwriting [19] could be used. This technique consists of a group members writing ideas on a sheet, for two or three minutes, then rotating the sheet to the left. This is repeated four or five times. Participants may re-write ideas based on what they receive or create new ones. All ideas are valid in this phase.

Material for this phase: We suggest using Brainwriting [19] for this phase instead of Brainstorming because all the participants write their ideas and contribute as equals. So, sheets should be printed for all the participants.

- Deliver (converge phase) selects the ideas according to the cost-benefit matrix [20]. This makes it easy to classify the ideas generated in the previous phase. Thus, this matrix allows to decide which ones end up being put into practice in the prototype.

The prototype should be able to reflect the location related features of this kind of games. That is, to show how the game behaves in each agreed relevant location.

Material for this phase: cost-benefit matrix printed in a size where ideas can be translated. For the ideas generated in the previous phase post-it could be used to make it easier to put them in the matrix. To make the prototype, all kinds of material should be provided, so that the groups can use their imagination to express their ideas.

Our proposed framework has been presented, in addition to the material that should be considered to conduct each phase.

\section{AN EXPERIENCE OF IN-SITU CO-DESIGN FOR MOBILE GAMES IN AN INDOOR SPACE}

This section describes an in-situ co-design experience facilitated using our conceptual framework presented in the previous section.

Eight ungraduated students of Computer Science of Faculty of Informatics (UNLP, Argentina) participated in this experience, half of them had knowledge on the design of mobile applications. The aim of this experience was to put into practice our conceptual framework to learn more about this kind of codesign. We divided the participants into two groups of four.

We developed an authoring tool [26] to assist in the task of in-situ co-design of Location-based Mobile Application which was used for some phases or activities of this experience as it is described below. Note that, this tool had been tested in [26] for in-situ co-design of a mobile application to a congress but it had not be tested for in-situ co-design mobile games.

The experience consists of an in-situ co-design of a mobile game inside the Faculty of Informatics' (UNLP, Argentina) building. Following, some features involved in this experience and how to deal with each phase of our framework are detailed.

- Discover. We have decided to use the authoring tool [26] for this phase, so, each participant installed this tool and received information to login. This tool allows to define relevant locations, so, each participant defined their own ones according to their perception.

Each group had its own workplace, so, this joined all the relevant locations defined by the participants of the group. This would be useful for the next steps.

The participants were required to resolve the "Design of a Location-based Game Mobile inside the building of the Faculty of Informatics". And, they were also told: "Using the Authoring Tool individually define all the relevant locations that could be of interest to the game." This was all the information that the participants had to define the relevant locations.

They had 20 minutes to use this tool. During this time they could not interact with other participants. As a meeting point, once the time was over, they had to return to the classroom from which they left.

Figure 2 shows some participants walking through the building. During the 20 minutes in which the tool was used, two people were observing the behavior of the participants and making photographic records of it.

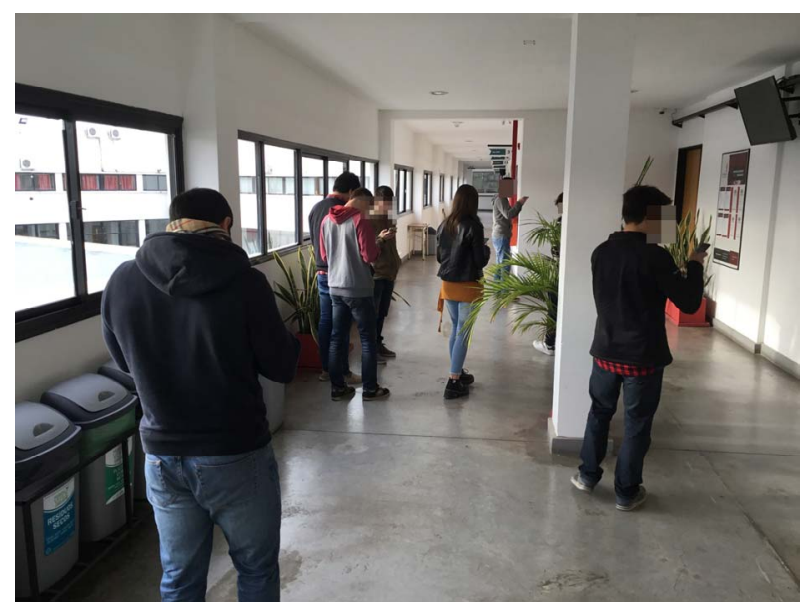

Fig. 2. Using our Authoring Tool to in-situ define relevant locations. 
Note that the tool uses the Situm API [30] to obtain the user's location. This requires to previously sense the WLAN signals inside the building with the Situm Mapping Tool [31]. This task involves walking in the corridors several times, to detect the signals of WLAN. The precision of these signals impacts when it is required to detect the user's location. When the user selects the option of creating a relevant location, the tool takes the WLAN location obtained from the Situm API to mark this on the indoor map.

Then, the participants were told to mark the relevant locations that they defined with the tool using pins on physical mock-ups of each floor; this is shown in Figure 3.

- Define. The groups were told to agree on the relevant locations that would be finally considered for the final version of the game; marking the agreed points with other labels in the physical mock-ups. In this phase, participants discussed the information and pictures to compare if everyone appreciated the same details in the coincident location. This is shown in Figure 4.

Using the tool, each group put down only visible the final relevant locations which were previously agreed upon. In this way, the tool helps to see the agreed relevant locations.

- Develop. A Brainwriting activity was put in practice, so, each participant was provided with a sheet of paper. They were told to write down ideas related to the game. Three minutes later the sheets were rotated to the left. This process which is shown in Figure 5, was repeated four times. Then, the participants wrote these ideas in post-it.

- Deliver. Using a cost-benefit matrix, each group classified their ideas putting each post-it in the corresponding sector of the matrix according to their criteria. This activity is shown in Figure 6. Then, each group selected which ideas could be implemented in the initial prototype.

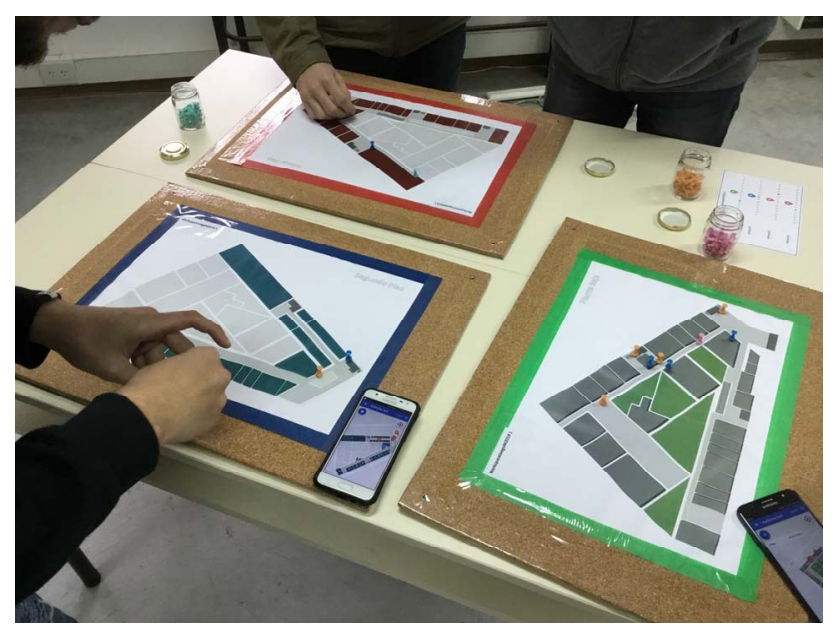

Fig 3. Participants marking the relevant locations that they had previously defined with the tool using pins on physical mock-ups of each floor.

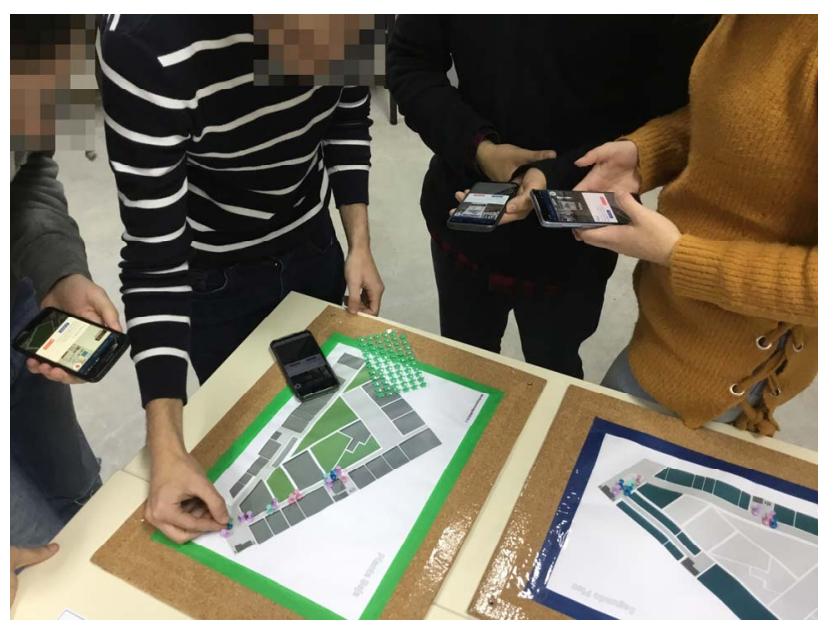

Fig. 4. A group agreeing on the relevant locations.

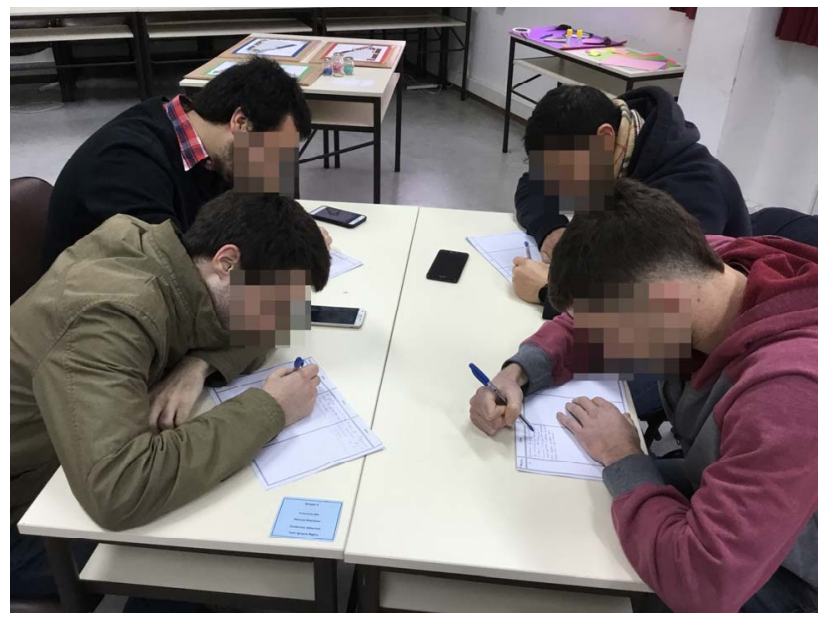

Fig 5. A Brainwriting activity.

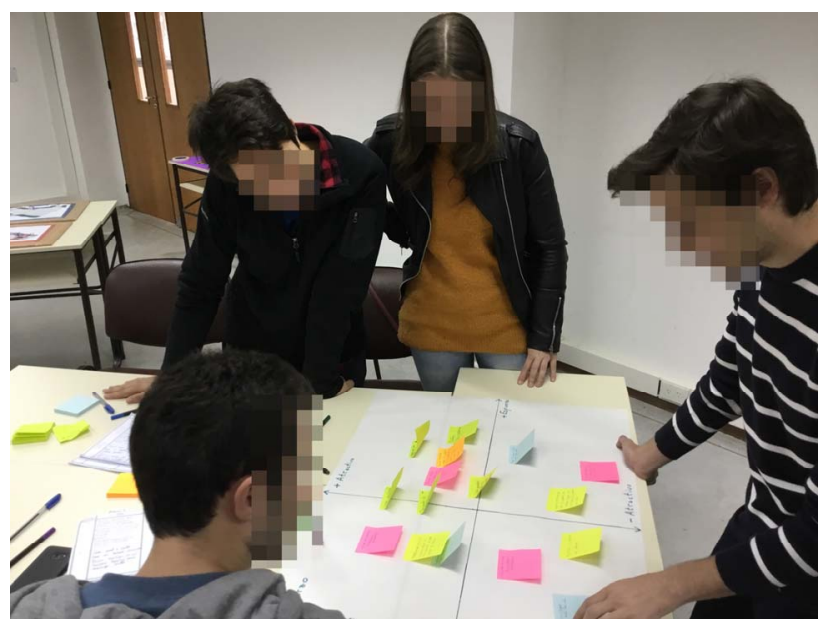

Fig 6. Using a cost-benefit matrix clasifies the ideas. 
Finally, each group proposed a prototype and they shot videos in which the game behavior in each relevant location is shown. Figure 7 shows a group during the filming of one of these videos.

In this section, it has been described an in-situ co-design experience facilitated using our conceptual framework. For each phase of this framework strategies used with the participants are presented.

\section{DISCUSION}

There are some interesting points about this kind of codesign which are analyzed below.

One of the important key points in this kind of experience is the role of the facilitator as he/she is aware of all participants and establishes the dynamic of each activity or produces some changes if it is necessary. In our experience, the facilitator has expertise in experiential learning and coaching. During this experience, for the Brainwriting activity, the facilitator reduced the time of each round in order to maintain the dynamic, and the participants' motivation. To do that, it is of interest to be aware of the group's approach to the activities and to adjust them accordingly.

Tools could help in some phases or activities, but others require discussion or interaction, such as the agreement of the relevant locations or prototype with physical materials. Sometimes, there is no tool to assist the process. In those cases, the phase of discovering could be put into practice by using printed maps, and so, each participant marks the relevant locations in them.

In case that a tool assists the process of co-design, then this data could be transformed into a specific implementation. In order to obtain games that could be adapted to new requirements or evolve over time [9] it is recommended to use the philosophy of separation of concerns to decouple each concept as is described in [26]. For example, decoupling the sensing mechanism of the data or services related to the game.

Preparation of the space and the materials is as essential as the facilitator role. First of all, it is important to distribute the tables to provide the participants with a comfortable place, in Figure 8 it can be seen how the physical space had been prepared for this experience.

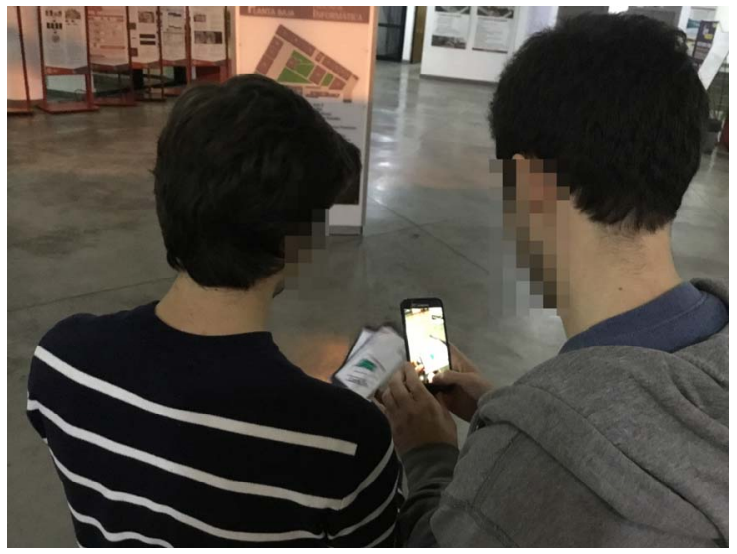

Fig 7. Defining the prototype.
In addition, each activity requires its own material, for example, for the prototype activities all material should be provided to the participant as it is shown in Figure 9. In the preparation, is important to take into account that the costbenefit matrix has been printed in a bigger size, so, the participants could distribute their ideas and could see all of them.

For the feature of the co-design experience presented in this paper, the profile of final user are students, so, the participants know about this topic. In other cases, when the participants require to empathise with the profile of final user other strategies could be used in the Discover phase as Persona [28] and Empathy Map [29] templates.

\section{CONLUSION AND FUTURE WORKS}

This paper has presented a conceptual framework for in-situ co-design of Location-based Mobile Games for indoor spaces which use some Design Thinking's resources to this task. For each phase, some strategies are listed to help facilitators of these types of experiences to consider what resources can be useful to this co-design.

An experience which used this conceptual framework is presented, so, this allows to be aware of how to conduct this kind

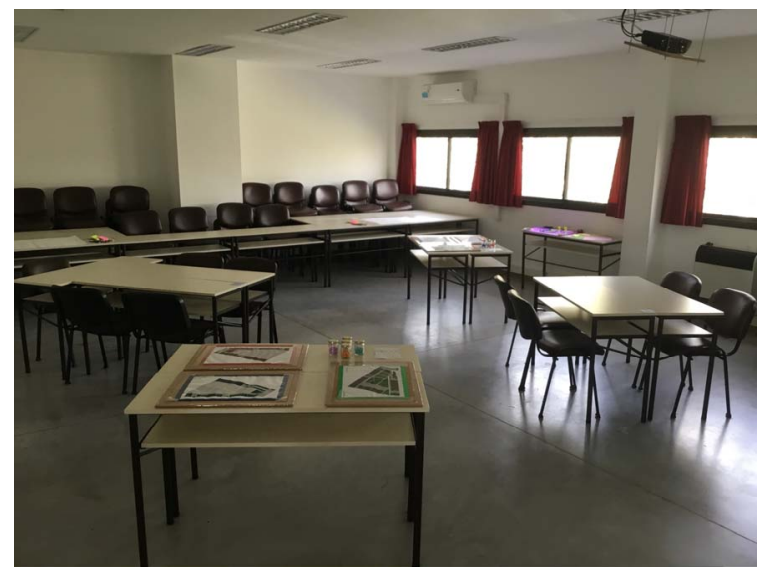

Fig. 8. Preparation of the physical space.

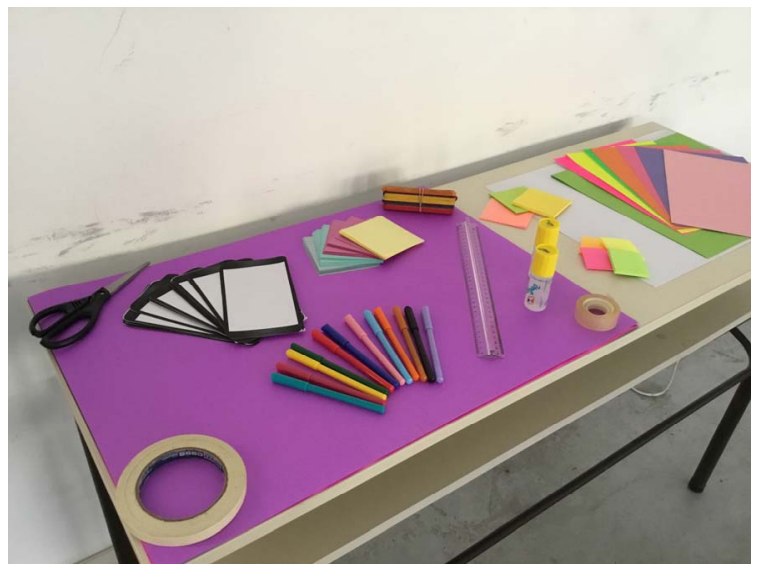

Fig. 9. Material for the prototype activity. 
of co-design. A discussion space is generated in relation to this kind of co-design to enrich the proposed conceptual framework.

As future work, we will explore more strategies, in particular, co-design prototypes for this kind of games which require to show how they behave in each relevant location.

\section{ACKNOWLEDGMENT}

The authors thank Juan Francisco Ale, Manuel Martínez, Lucio Ernesto Gargiulo, Sebastian Villena, Juan Ignacio Riglos and Dante Barba for their participation in the in-situ co-design experience.

\section{REFERENCES}

[1] A.G. LeBlanc, and J.P. Chaput, "Pokémon Go: a game changer for the physical inactivity crisis?". Preventive medicine, vol. 101, pp. 235-237, 2017.

[2] A. Basiri, E.S. Lohan, T. Moore, A. Winstanley, P. Peltola, C. Hill, A. Pouria, and P. Figueiredo e Silva, "Indoor location based services challenges, requirements and usability of current solutions". Computer Science Review, vol. 24, pp. 1-12, 2017.

[3] K. Papangelis, M. Metzger, Y. Sheng, H.N. Liang, A. Chamberlain, and T. Cao, "Conquering the city: Understanding perceptions of mobility and human territoriality in location-based mobile games". In Proceedings of the ACM on Interactive, Mobile, Wearable and Ubiquitous Technologies, vol. $1, \mathrm{n}^{\circ} 3$, articule 90, 2017.

[4] S. Xanthopoulos, and S. Xinogalos, "Opportunities and challenges of mobile location-based games in education: Exploring the integration of authoring and analytics tools". In 2018 IEEE Global Engineering Education Conference (EDUCON), IEEE, pp. 1797-1805, 2018

[5] P. Santos, D. Hernández-Leo, and J. Blat, "To be or not to be in situ outdoors, and other implications for design and implementation in geolocated mobile learning". Pervasive and Mobile Computing, vol. 14, pp. 17-30, 2014

[6] L.F. Maia, C. Nolêto, M. Lima, C. Ferreira, C. Marinho, W. Viana, and F. Trinta, "LAGARTO: A LocAtion based Games AuthoRing TOol enhanced with augmented reality features". Entertainment computing, vol. 22, pp. 3-13, 2017.

[7] C. Jones, and K. Papangelis, "Reflective Practice: Lessons Learnt by Using Board Games as a Design Tool for Location-Based Games". In The Annual International Conference on Geographic Information Science, Springer, pp. 291-307, 2019

[8] T. Brown, "Design thinking". Harvard business review, vol. 86, nº 6, 8492, 2008

[9] D. Weyns, M. Caporuscio, B. Vogel, and A. Kurti, "Design for sustainability $=$ runtime adaptation $U$ evolution". In Proceedings of the 2015 European Conference on Software Architecture Workshops, ACM, pp. 62-69, 2015.

[10] F. Shakouri, and F. Tian, "Avebury Portal - A location-based augmented reality treasure hunt for archaeological sites". In Proceedings of International Conference on E-learning \& Games (Edutainment 2018), 2018.

[11] J. Melero, and D. HernÁndez-Leo, "Design and implementation of location-based learning games: Four Case Studies with 'QuesTInSitu: The Game". IEEE Transactions on Emerging Topics in Computing, vol. 5, No 1, IEEE Press, pp. 84-94, 2017.

[12] F.M. Alconada Verzini, J.I. Tonelli, C. Challiol, A.B. Lliteras, and S.E. Gordillo, "Combing location-aware applications with in-situ actors performances". In Proceedings of the 2015 Workshop on Narrative \& Hypertext, ACM, pp. 27-31, 2015.

[13] A. Jones, B. Gyori, C. Hargood, F. Charles, and D. Green, "Shelley's Heart: experiences in designing a multi-reader locative narrative". In Proceedings of The 7th International Workshop on Narrative and Hypertext hosted at ACM Hypertext and Social Media (NHT'18), ACM, 5 pages, 2018.
[14] J.D. Wake, F. Guribye, and B. Wasson, "Learning through collaborative design of location-based games". International Journal of ComputerSupported Collaborative Learning, vol. 13, no 2, pp. 167-187, 2018

[15] C. Hargood, M. Weal, and D. Millard, "The storyplaces platform: Building a web-based locative hypertext system". In Proceedings of the 29th on Hypertext and Social Media (HT'18), ACM, pp. 128-135, 2018.

[16] Design Council: https://www.designcouncil.org.uk/news-opinion/whatframework-innovation-design-councils-evolved-double-diamond (last access: 19/08/2019)

[17] N.M.C. Valentim, W. Silva, and T. Conte, "The students' perspectives on applying design thinking for the design of mobile applications". In Proceedings of the 39th International Conference on Software Engineering: Software Engineering and Education Track, IEEE Press, pp. 77-86, 2017.

[18] C. Challiol, "Challenges of teaching to the new generation of IT students". In IT Profesional: Student Forum, IEEE Computer Society. DOI: 10.1109/MITP.2019.2932813. 2019. In Press.

[19] P.A. Heslin, "Better than brainstorming? Potential contextual boundary conditions to brainwriting for idea generation in organizations". Journal of Occupational and Organizational Psychology, vol. 82, $\mathrm{n}^{\circ}$ 1, pp. 129$145,2009$.

[20] Gartner Cost Value Matrix: https://www.gartner.com/en/documents/2801719 (last access: $19 / 08 / 2019)$

[21] A. Fortier, G. Rossi, S.E. Gordillo, and C. Challiol, "Dealing with variability in context-aware mobile software". Journal of Systems and Software, vol. 83, $\mathrm{n}^{\circ}$ 6, pp. 915-936, 2010 .

[22] C. Challiol, A.B. Lliteras, and S.E. Gordillo, "Mobile learning applications: Exploring location sensing mechanisms". In: AgredoDelgado V., Ruiz P. (eds) Human-Computer Interaction. HCI-COLLAB 2018. Communications in Computer and Information Science, Springer, Cham, vol. 847, pp 184-198, 2018.

[23] E.R. Gómez-Torres, C. Challiol, and S.E. Gordillo, "Context-aware mobile applications: Taxonomy of factors for building approaches". In 2018 IEEE XXV International Conference on Electronics, Electrical Engineering and Computing (INTERCON), IEEE Press, pp. 1-4, 2018.

[24] F.M. Alconada Verzini, J.I. Tonelli, C. Challiol, A.B. Lliteras, and S.E. Gordillo, "Authoring tool for location-aware experiences". In Proceedings of the 2015 Workshop on Narrative \& Hypertext, ACM, pp. 21-25, 2015.

[25] A.M. Zimbello, F.M. Alconada Verzini, C. Challiol, A.B. Lliteras, and S.E. Gordillo, "Authoring tool for location-based learning experiences". In 2017 IEEE/ACM 4th International Conference on Mobile Software Engineering and Systems (MOBILESoft), IEEE Press, pp. 211-212, 2017.

[26] F.I Mendiburu, C. Challiol, and S.E. Gordillo, "Herramienta de autor para co-diseñar in-situ Aplicaciones Móviles basadas en Posicionamiento". In Proceedings of the Simposio Argentino de Ingeniería de Software (ASSE) - JAIIO, 2019. In Press.

[27] A.B. Lliteras, C. Challiol, and S.E. Gordillo, "Location-based mobile learning applications: A conceptual framework for co-design". In Proceedings of Twelfth Latin American Conference on Learning Technologies (LACLO), IEEE Press, pp.358-365, 2017.

[28] S.T. Acuña, J.W. Castro, and N. Juristo, "A HCI technique for improving requirements elicitation". Information and Software Technology, vol. 54, $\mathrm{n}^{\circ} 12$, pp. 1357-1375, 2012.

[29] D. Gray, S. Brown, and J. Macanufo, "Gamestorming: A playbook for innovators, rulebreakers, and changemakers”, O'Reilly Media, Inc., 2010.

[30] Situm API: https://developers.situm.es (last access: 23/10//2019)

[31] Situm Mapping Tool: https://play.google.com/store/apps/details?id=es.situm.maps\&hl=es_AR (last access: 23/10//2019) 